\title{
OLHARES PARA A DIVERSIDADE, INCLUSÃO ESCOLAR E EXCLUSÃO SOCIAL: CONTRIBUIÇÕES DA EDUCAÇÃO SOCIAL
}

\section{MIRADA HACIA LA DIVERSIDAD, INCLUSIÓN ESCOLAR Y EXCLUSIÓN SOCIAL: CONTRIBUCIONES DE LA EDUCACIÓN SOCIAL}

\section{GAZES TO THE DIVERSITY, SCHOOL INCLUSION AND SOCIAL EXCLUSION: SOCIAL EDUCATION CONTRIBUTIONS}

Fabiano Antonio dos SANTOS ${ }^{1}$

Bárbara Amaral MARTINS ${ }^{2}$

Mônica de Carvalho Magalhães KASSAR ${ }^{3}$

Os anos da década de 1990 marcam importantes mudanças nos discursos envolvendo os direitos humanos, as relações entre as políticas nacionais e os organismos internacionais. São resultado de disputas por projetos sociais antagônicos que visam apresentar alternativas de combate à exclusão e promotoras de inclusão social, sobretudo, por meio da educação. Embora o tema dos direitos humanos tenha sido construído no pós-guerra e os primeiros acordos assinados durante a Guerra Fria, os anos de 1990 favoreceram outra perspectiva a essa temática (KOERNER, 2002) e, também, novas formas de entendimento entre os poderes locais (nacionais) e o internacional (DALE, 2004). O foco nos direitos humanos e em outras questões que apontam à diversidade e à exclusão social ocorre em um período de forte perspectiva neoliberal, de modo que, à primeira vista, parece haver um descompasso ou contraste entre "a agenda política dos Estados nacionais, em que o ajuste estrutural e o equilíbrio macroeconômico marcaram o debate político e acadêmico" e "o tratamento de temas sociais [que] marcou a agenda dos direitos humanos das Nações Unidas na década de noventa (KORNER, 2002, p. 88).

Nesse período, a atenção ao cumprimento da escolaridade obrigatória das matrículas das crianças em idade escolar (escola como lócus por excelência das crianças) aumenta nos países

\footnotetext{
${ }^{1}$ Universidade Federal de Mato Grosso do Sul - (UFMS), Corumbá - MS - Brasil. Professor do curso de pedagogia e do Programa de Pós-Graduação em Educação. Doutorado em Educação (UFSC). ORCID: https://orcid.org/0000-0002-7703-8520. E-mail: fabiano.santos@ufms.br

${ }^{2}$ Universidade Federal de Mato Grosso do Sul (UFMS), Corumbá - MS - Brasil. Professora Adjunta do curso de Pedagogia e do Programa de Pós-Graduação em Educação. Doutorado em Educação (UNESP). ORCID: https://orcid.org/0000-0003-4278-1661.E-mail: barbara.martins@ufms.br

${ }^{3}$ Universidade Federal de Mato Grosso do Sul - (UFMS), Corumbá - MS - Brasil. Professora do Programa de Pós-Graduação em Educação. Doutorado em Educação (UNICAMP). ORCID: https://orcid.org/0000-0001-55776269. E-mail: monica.kassar@ufms.br
} 
em que não se cumpria a universalização escolar. Especificamente no Brasil, o foco é fortalecido pela intersetorialidade entre as políticas educacionais e demais políticas sociais, prevista nos diferentes planos plurianuais federais. É, ao mesmo tempo uma demanda do modelo econômico que transfere para a escola a tarefa de ampliar a formação de capital humano (FRIGOTTO, 1995) e uma resposta às demandas de grupos sociais de acesso à educação. Se a matrícula escolar é compromisso dos estados nacionais e um direito humano, sob a perspectiva da Declaração Universal dos Direitos Humanos - DUDH (UN, 1948), sua efetivação nem sempre é assegurada e, quando ocorre, nem sempre possibilita a atenção para inúmeras condições em que as crianças, adolescentes e suas famílias estão envolvidos. Um conjunto de políticas sociais (saúde, assistência social, trabalho etc.) deve estar articulado para atender a população. Nesse contexto, a educação social faz-se presente ${ }^{4}$, seja como campo de estudo na formação de professores, inclusive nos cursos de Pedagogia, seja como campo de atuação em equipamentos públicos na efetivação do Sistema Único da Assistência Social, do Sistema Único de Saúde etc.

Como lembra Diaz (2006, p. 92), “o indivíduo socializa-se dentro e fora da instituição escolar e, por isso, a educação social deve efectuar-se em todos os contextos nos quais se desenvolve a vida do ser humano".

A educação social, construída como estratégia de atenção aos "inadaptados", de certa forma, como resposta às necessidades do Estado-providência (DIAZ, 2006), vem se reconfigurando em diferentes países (RIBEIRO, 2006), construindo novas práticas e perspectivas, buscando resoluções para os problemas decorrentes da exclusão social inerente a esta sociedade. A exclusão social gera, assim, duas importantes preocupações que acompanham as discussões da educação social: movimentos em prol da garantia de direitos e a "nova questão social” (RIBEIRO, 1998). Estas preocupações dão conta de abordar, ao mesmo tempo, os aspectos de exclusão econômica e social, mais evidentes no modelo de produção capitalista mas, também, apontam para atendimento das novas questões da contemporaneidade como gênero, diversidade, atendimento aos direitos fundamentais, entre outras. Atualmente, encontramo-nos em tempos de acentuadas tensões no que se refere à garantia dos direitos econômicos, sociais e humanos. Com atenção a esse cenário e aos desafios contemporâneos, este dossiê propõe-se a abrir espaço para diferentes temáticas que possam contribuir para a

\footnotetext{
${ }^{4}$ Social se dá nos anos 1990 em um contexto de crescente proliferação de políticas neoliberais. Surge na Europa para atender os órfãos da Segunda Guerra Mundial, vai se ampliando para todo o mundo e chega ao Brasil para atender, primeiramente, os chamados desajustados. Somente com o passar dos anos, estudos vão aprimorando a compreensão da educação social conferindo visão mais crítica.
} 
construção de possibilidades de sociedades viáveis para que, como propõe Ribeiro (2006, p. 156), seja possível forjar uma vida que "conjugue a humanização, afirmada por Freire (1981a), com a emancipação, pensada por Marx (1993)".

\section{Educação social e a construção de ações contra hegemônicas}

Atribuir uma qualidade (social) ao termo educação parece redundância uma vez que é evidente que toda educação é, inerentemente, social. Esta afirmação tem nos acompanhado enquanto Programa de Pós-Graduação cuja área de concentração é a Educação Social. Com o tempo, percebemo-nos envolvidos em uma questão muito complexa, sendo necessário aprofundar a compreensão desse conceito e fugindo, assim, de respostas pouco problematizadoras e explicativas. Este dossiê é o resultado do amadurecimento do Programa de Pós-Graduação em Educação da Universidade Federal de Mato Grosso do Sul, Campus do Pantanal, após dez anos de sua criação. Hoje, parece-nos fundamental o questionamento de Ribeiro (2006, p. 160), sobre a qualidade "social" somada ao conceito de educação para melhor definir nossa compreensão sobre o termo: "Se o social, como o mundo de relações em que se efetuam os processos de sociabilidade, é o substrato no qual se realiza a educação, como entender que esta ocupe o lugar do substantivo ou daquele que é adjetivado na expressão "educação social”?

Pretendemos apresentar, ao longo deste Dossiê, que sim, toda educação é social, mas nem sempre os aspectos sociais a que denominamos de transformadores acompanham as práticas educativas. Em outras palavras, ainda que todo o trabalho educativo envolva "o social", por ser uma produção humana, nem sempre tal trabalho está permeado por uma visão de totalidade do ser humano ou está voltado para a construção alternativa de meios de existir no mundo, de formas que possam ser transformadoras da realidade extremamente excludente que vivemos. Por isso, o social é mais que uma qualidade; ao se incorporar ao conceito de educação se transforma em um substantivo que dá nome a toda prática formativa contra hegemônica, que visa, como vamos acompanhar aqui, construir uma escola mais inclusiva, uma sociedade baseadas em outros valores, que tenha como horizonte o processo revolucionário em todos os sentidos.

Refletir sobre o significado da educação social é, antes de tudo, uma ação política na medida em que nos leva a analisar a sociedade vigente e, com ela, seus mecanismos de exclusão social. Nessa direção, Saviani (1988) nos ensina que educação e política são práticas sociais indissociáveis e interdependentes no âmago dos interessantes antagônicos que caracterizam a 
sociedade de classes, porém, embora a primeira apresente maior dependência em relação à segunda - a qual estabelece suas condições objetivas -, igualmente dispõe de relativa autonomia para atuar em favor das camadas menos favorecidas.

Analisando do ponto de vista da formação, a educação tem ocupado papel de destaque na sociedade capitalista desde o período de transformações da organização do trabalho baseadas no fordismo e toyotismo. Tanto o primeiro como o segundo, com suas devidas diferenças em termos de organização do trabalho, consideraram a educação peça chave para a formação de um novo trabalhador e como processo de valorização do capital. Esses 'novos' tipos de produções racionalizadas demandaram a formação de um 'novo' tipo de homem capaz de se ajustar às 'novas' técnicas de trabalho, aos 'novos' valores considerados adequados para a sociedade capitalista. A alienação passa a ser necessidade primordial, já que a introjeção de valores torna-se o método principal de controle social, em oposição aos métodos coercitivos anteriormente adotados. Educar pelo consenso foi uma das principais constatações que Gramsci (2011) fez ao estudar o americanismo e fordismo, ao analisar as estratégias usadas pelo capital para construção de sua hegemonia.

A estrutura curricular brasileira, por exemplo, é materialização de que a educação vai assumindo papel importante na formação de capital humano, ajustada às demandas do contexto econômico. O destaque que as reformas vão dando à pedagogia de competências (RAMOS, 2001) seja, talvez, o melhor exemplo disso. A mais atual destas mudanças foi a implementação da Base Nacional Comum Curricular e a adoção das competências como conteúdos privilegiados para se trabalhar nas escolas (inclusive competências socioemocionais, além das já conhecidas competências cognitivas).

A educação é uma atividade intencional, envolve um conjunto de práticas sistematizadas que atuam para a formação humana. Essa definição nos revela que, independentemente de analisarmos os processos de educação formal ou não-formal, seu contexto é de extrema relevância para compreendermos suas finalidades. As finalidades educativas, sejam elas voltadas a educação formal ou não formal, nos ajudam a compreender, ao mesmo tempo, que não se pode desvincular os aspectos econômicos dos aspectos políticos, culturais e sociais. Dito de outra forma, a educação é resultado da intervenção humana para perpetuar sua existência, para produzir a humanidade no homem (SAVIANI, 1988). Assim, a educação resulta do contexto social, político, econômico e cultural nos quais estão implícitas relações de disputa por hegemonia. Resultam de um jogo de forças em que se defrontam sistemas de valores, ideologias, interesses particulares e de classes, e que geram movimentos hegemônicos e contra hegemônicos. 
A educação social, a despeito de sua origem, pode ser gestada justamente para servir de estratégia contra hegemônica a este modelo econômico; para construir possibilidades de enfrentamento, para estabelecer formas de agir no mundo, para se manifestar contra o processo de exclusão inerente ao projeto de sociedade capitalista (RIBEIRO, 2006). Neste sentido, concordamos com Ribeiro (2006) quando formula a hipótese sobre as disputas por hegemonia e o papel que a educação ocupa neste cenário. Para a autora,

[...] existe uma disputa entre projetos sociais e educacionais contraditórios, resultando, daí, estratégias de combate à exclusão e promotoras de inclusão, encarnadas em concepções e práticas de educação social, como resposta às demandas de políticas sociais públicas provenientes das populações de crianças e jovens em situação de vulnerabilidade (RIBEIRO, 2006, p. 156).

A educação social oferece possibilidades de pensarmos práticas inclusivas de formação, contrárias ao processo de exclusão social gerado pelas sociedades em que imperam o culto à competitividade e o cultivo à desigualdade. Analisando criticamente a estratégia capitalista de precarização do trabalho, a exclusão gerada pelo desemprego estrutural tende a gerar um fenômeno que Kuenzer (2004) denominou de “exclusão includente”, ou seja, a perda do emprego formal empurrando uma massa de trabalhadores cada vez maior para o mundo da informalidade, juntamente à disseminação da valorização do empreendedor autônomo. Nesta lógica, o que a educação social busca superar é justamente outro fenômeno apontado por Kuenzer (2004), o da "inclusão excludente", ou seja, o movimento de inclusão proporcionado pelas políticas sociais de cariz neoliberal que objetivam amenizar as crises cíclicas do capital (MESZÁROS, 2005).

Assim, através dos processos de inclusão excludente, a educação escolar e não escolar se articulam dialeticamente aos processos de exclusão includente existentes no mundo do trabalho, fornecendo ao cliente - o capital - a força de trabalho disciplinada técnica e socialmente, na medida das suas necessidades, como reza a boa cartilha do toytismo; como já se afirmou anteriormente, a expressão pedagógica deste princípio se dá através da pedagogia das competências com suas categorias, [...] que demanda estudos aprofundados para que se elucidem seus propósitos e seus mecanismos enquanto nova pedagogia a serviço do capital (KUENZER, 2004, p. 92).

Martins (1997) corrobora a ideia de inclusão excludente ao afirmar que o que denominamos como exclusão é antes “uma inclusão precária e instável, marginal” (p. 26, grifo do autor), que reserva lugares residuais para parte da população, objetivando reproduzir as estruturas vigentes e, ao mesmo tempo, conformar, a fim de que não ocorra a transformação da sociedade que vitima grandes contingentes. 
Explicar o significado que atribuímos à educação social a partir do binômio exclusão/inclusão possibilita, portanto, localizar seu campo de atuação. Ribeiro (2006) nos ajuda a localizar este campo quando afirma que o termo exclusão gera ações contra hegemônicas, manifestadas pela criação de novos movimentos sociais, ampliando a compreensão dos problemas que fazem parte de nosso cotidiano e, muitas vezes, são naturalizados. A educação social, neste campo de tamanha exclusão (inclusão excludente, para usarmos o termo de Kuenzer), procura evidenciar os expropriados dos meios de produção, os trabalhadores que possuem, apenas, sua força de trabalho como propriedade e as desigualdades nas relações sociais. A educação social pode buscar, ainda, revelar que em meio ao discurso de aparente igualdade no capitalismo, reside a opressão, a dominação, a discriminação de todas as formas. O que se pretende com a educação social é o rompimento com todas as formas de exploração e desapropriação produzidas e, para isso, uma educação crítica, transformadora e vinculada às lutas sociais é fundamental.

É importante destacar que ao desenvolvermos formas de compreender melhor a educação social enquanto conceito, não excluímos a educação escolar, uma vez que estes princípios transformadores devem fazer parte de seu objetivo. Aqui, parece que chegamos a uma ideia, ainda que bem ampla, sobre educação social: tratam-se de práticas que possuem princípios transformadores, que buscam estabelecer uma nova ordem social e, para isso, atuam em diferentes realidades. É mais comum, dado seus aspectos contra-hegemônicos, vincular seu campo de atuação à área não formal, principalmente à educação popular. Entretanto, o que apresentamos neste dossiê é um desafio: compreender a educação social não somente como modalidade de ensino, como prática pedagógica, mas, também, como princípio orientador e, como tal, possível de ser observada em todos os âmbitos formativos.

A educação social, nesta perspectiva, pode englobar ações de duas ordens, pelo menos: uma de luta pela garantia da educação como direito humano, que se manifesta na concepção que assume como estratégia contra hegemônica; e outra de construir práticas inclusivas nos ambientes de formação humana (sejam eles escolares ou não). Considerando essas duas ordens de possibilidades (concepção de educação/formação e prática pedagógica) os textos deste dossiê debatem a educação numa perspectiva social, o que significa olhar para a fenômeno educativo desde a perspectiva dos explorados, das minorias, da classe trabalhadora.

$\mathrm{Na}$ sequência, para fins didáticos de apresentação dos trabalhos que compõem este dossiê, separamos os textos em dois grupos. Cabe ressaltar que, de fato, estes aspectos aqui colocados separadamente são indissociáveis, uma vez que a prática pedagógica em diferentes 
contextos tem base de sustentação nas diferentes concepções e nas abordagens possíveis para o trato com a educação social.

\section{A Educação social como concepção: perspectivas e estratégias para a construção}

de ações contra hegemônicas reúne um conjunto de artigos que trata da educação social enquanto concepção e, portanto, evidencia as diversas possibilidades de abordar o tema do ponto de vista epistemológico e metodológico. A ideia central, portanto, é apresentar que a educação social como concepção que pode ser tomada como contrária à exclusão, com finalidade de atendimento aos direitos fundamentais do ser humano, chamando a atenção para aspectos tidos como naturalizados e que, analisados mais detidamente, se revelam como manifestações da cultura individualista, opressora e meritocrática da sociedade vigente. Essa percepção é proposta, no conjunto de trabalhos a seguir, a partir de diferentes matizes teóricoepistemológicos.

O primeiro texto, de Ernesto Candeias Martins, denominado a educação social nos novos espaços e tempos: as realidades entroncadas da intervenção social e educativa, argumenta que as últimas décadas tem produzido uma série de fatores sociais, econômicos, tecnológicos, culturais, políticos, responsáveis por emergir novas visões/enfoques de tratar a questão da aprendizagem, as quais sustentam novas possibilidades pedagógicas para serem satisfeitas, segundo os desafios e complexidade da sociedade. Neste sentido, a Educação Social e a Pedagogia Social apresentam-se como resposta a tais demandas, sendo tratadas como práticas interculturais que se constituem, segundo o autor, em serviço e direito social de legitimação da cidadania. Ainda, a Educação Social e Pedagogia Social refletem sobre situações e conflitos sociais humanos, sabendo que qualquer espaço no tempo é próximo ao processo de aprender a aprender, propício a desenvolver capacidades ou competências nos indivíduos, com destaque para o papel das instituições educativas e da família, e, por isso, o pedagógico-social implica a necessidade atual de abertura da educação à vida em toda a sua diversidade na comunidade. $\mathrm{O}$ autor conclui que é preciso ampliar a visão formativa para além dos limites escolares, pois, para ele, aprendemos em diversos contextos e espaços não-escolares e a educação social constitui-se como peça fundamental de ação promotora e dinamizadora de uma sociedade que educa e de uma educação integral, que ajuda/apoia, mediante a educação de modo a evitar ou reparar dificuldades e conflitos sociais. Afirma, ainda, que a Educação Social e a Pedagogia Social constituem uma 'práxis' cotidiana nos contextos socioeducativos formais e não formais, especialmente na relação 'Escola-Comunidade', exigindo mudanças nos estilos dos professores e nos modelos organizativos da escola, gerando-se uma estreita colaboração 
entre o educador social e os outros profissionais que atuem em prol de uma aprendizagem social.

Ainda de forma introdutória à educação social como concepção e garantidora de direito, Dhyovanna Guerra e Ireni Marilene Zago Figueiredo apresentam seu texto denominado Políticas Sociais e o direito a educação. As autoras argumentam em favor da educação como direito público subjetivo e, para isso, realiza uma pesquisa bibliográfica e documental. Para as autoras, o Direito à Educação é resultado de uma demanda expressa pela luta dos movimentos sociais, que resultou na ampliação do período de escolarização obrigatória e gratuita. Nos oferecem, assim, uma visão dialética entre objetivação da educação como direito e sua materialização nas políticas sociais. Chamam a atenção para a necessidade de maior clareza dos limites e possibilidades das Políticas Sociais no capitalismo, na garantia e efetividade dos Direitos Sociais. Concluem que, embora a proclamação de direitos sociais como a educação tenha respaldo legal na legislação brasileira em termos de efetivação do acesso à escola, os impeditivos econômicos e sociais, manifestados na mercantilização da educação, por exemplo, restringem o acesso (e acrescentaríamos a permanência) à escola a um significativo contingente populacional.

Ainda na direção de compreender a educação como direito social Hellen Jaqueline Marques e Newton Duarte, em artigo denominado A Pedagogia Histórico-Crítica em defesa de uma educação revolucionária, insistem na importância da educação tanto como satisfação das necessidades humanas como atendimento aos direitos sociais fundamentais. A argumentação dos autores é de que a escola deve contribuir para a superação da sociedade capitalista, ainda que esteja inserida neste contexto. Para isso, defendem como papel da escola o desenvolvimento do pensamento teórico, capaz de trabalhar com a dialética entre os eventos aparentes e os processos essenciais, tomando a atuação deliberada do professor no sentido da produção do pensamento teórico nos alunos. Os autores apresentam a pedagogia HistóricoCrítica como a mais indicada para produzir uma educação verdadeiramente revolucionária, pois em sua essência está o objetivo de superação da sociedade capitalista o que reflete sua prática transformadora.

Outro texto que vem a público defender a concepção de educação como direito é o produzido por Alessandra de Oliveira Maciel, Ana Ignez Belém Lima e José Airton de Freitas Pontes Junior, intitulado Estágio supervisionado e residência pedagógica: possibilidades para formação docente crítica. Neste artigo, os autores procuram apresentar a importância da educação numa visão ampla de formação inicial, a partir de um estudo de caso do papel do Estágio Curricular Supervisionado (ECS) e da Residência Pedagógica (RP) como possíveis 
espaços de formação docente crítico-reflexiva. Retomando a ideia da educação social como concepção crítica, reflexiva e contra hegemônica, é possível inserir este texto como materialização da importância de adoção de políticas públicas voltadas à formação crítica, o que, segundo os autores, possibilita intervenções pedagógicas igualmente mais críticas e contextualizadas. Os autores fazem a defesa, neste contexto de visão ampla e crítica sobre as políticas de formação, de que a trajetória profissional é construída coletivamente e continuamente, não se reduzindo a um único evento. Concluem que, tanto o Estágio como a Residência Pedagógica auxiliam o desenvolvimento de uma ação docente em que teoria e prática caminham juntas e o pensamento crítico-reflexivo constitui-se elemento indispensável.

Ainda na defesa da educação como direito humano as autoras Rosana Carla do Nascimento Givigi, Denise Meyrelles de Jesus, Raquel Souza Silva e Juliana Nascimento de Alcântara, em artigo denominado Políticas educacionais inclusivas e a intersetorialidade com as políticas sociais: interfaces Brasil/Canadá propõem analisar as políticas educacionais inclusivas e a intersetorialidade com as políticas sociais em uma perspectiva comparada, no Brasil e Canadá. Com históricos distintos, a educação social no Brasil e no Canadá acabam agindo, na atualidade, com os mesmos objetivos, quais sejam: desenvolver ações sociais e pedagógicas que enfrentem a marginalização dos grupos em situação de vulnerabilidade, articulando as práticas pedagógicas formais com as informais, seja na escola ou fora dela. As autoras revelam que, desde os anos 1980, o Canadá tem manifestado a preocupação com a educação inclusiva da pessoa com deficiência em suas normativas, tornando obrigatória a inclusão destas pessoas na escola regular. Os anos posteriores, naquele país, presenciam a criação de uma série de programas, diretrizes para a escola, de serviços disponibilizados para professores e alunos. As autoras comentam que diferentemente, no Brasil, somente com a promulgação da LDBEN 9394/96 que a educação especial passa a ser considerada uma modalidade de ensino, possibilitando muitos movimentos em defesa da inclusão das pessoas com deficiência na escola regular. Concluem que há importantes diferenças entre as políticas sociais desenvolvidas entres os países pesquisados e isso se deve ao lugar que ocupam na economia mundial, sendo o Brasil pertencente a periferia do capitalismo e o Canadá fazendo parte do grupo de países centrais. Diante destas diferenças, as autoras apontam que a implementação das políticas de inclusão escolar/Educação Especial nos dois países resultou em distintas práticas organizativas, com diferentes equipamentos de apoio. Chamam a atenção para o perigo que o tempo presente revela, já que ao longo dos últimos dez anos há um evidente avanço no desenvolvimento de políticas de inclusão, mas que o atual momento político demonstra o retorno da exclusão escolar e redução da garantia de políticas sociais. Neste mesmo 
contexto de crise, as autoras afirmam que o Canadá tem garantido políticas sociais e educacionais inclusivas.

De fato, as discussões sobre os direitos se manifestam como pano de fundo importante para a compreensão da educação social enquanto perspectiva. Se até o momento o material apresentado reivindica a educação como poderosa ferramenta de transformações sociais, é importante ter clareza que ela não é suficiente para que uma nova sociedade efetivamente se construa (ainda que sua participação seja de grande relevância). Considerando, assim, a multiplicidade de aspectos que se fazem necessários para que as mudanças que delimitam o horizonte da educação social se concretize, apresentamos o texto elaborado por Bárbara Amaral Martins e Fabiano Quadros Rückert, intitulado Educação e pobreza: o Programa Bolsa Família na percepção dos estudantes do ensino médio em Corumbá-MS. Aqui, os autores nos convidam a problematizar o olhar que foi se construindo em torno de um dos programas sociais de maior relevância da história recente brasileira, o Programa Bolsa Família (PBF). Destacando as percepções de 23 estudantes do ensino médio (dos quais 14 eram beneficiários do programa), o texto mostra o desafio de construir condições objetivas e subjetivas para que o Estado cumpra seu papel, e que este seja efetivamente compreendido pela sociedade não como um favor, mas como mais um direito daqueles excluídos. A pesquisa realizada conclui que, embora a visão sobre o programa seja positiva em sua maioria, há graus distintos desta positividade e poucos foram os estudantes que mostraram compreensão de que o programa está relacionado à garantia de direitos mínimos ou a busca pela superação da pobreza extrema, inerente à sociedade capitalista. Por fim, os autores acreditam que as questões relacionadas ao PBF remetem aos conceitos de cidadania, políticas públicas e equidade social, e, consequentemente, demandam maior atenção das escolas e dos segmentos sociais diretamente envolvidos no ensino escolar.

O debate acerca da inclusão não faz parte apenas das políticas públicas de Estado, ele está presente em diferentes esferas da sociedade. Considerando a multiplicidade de discursos, até mesmo as relações entre eles (discursos produzidos por políticas de Estado e outras instituições sociais), é que as autoras Inés Rodríguez Moyano e Lucrecia Rodrigo procuram compreender como se produzem e as intencionalidades dos discursos sobre educação, inclusão e qualidade disseminados por Organizações Internacionais, tendo como referência as políticas de avaliação na Argentina. Assim, o tema deste artigo, que tem o título de Educação, inclusão e qualidade: os discursos das Organizações Internacionais e as políticas de avaliação na recente Argentina, amplia para o contexto sul-americano o olhar da educação social como concepção. Para tanto, aborda propostas de inclusão educacional que fazem parte das agendas 
de desenvolvimento da Organização das Nações Unidas para a Educação, a Ciência e a Cultura (UNESCO) e da Organização dos Estados Americanos (OEI), e investiga a ligação entre esses discursos e a orientação das políticas de avaliação na Argentina recente. Analisando documentos produzidos desde os anos 1990, principalmente aqueles elaborados a partir de 2000, a hipótese central do texto é que o discurso realizado por estes Organismos Internacionais sobre educação inclusiva se apoia nos conceitos de qualidade e aprendizagem e adquirem centralidade para os programas de avaliação. As autoras concluem que a defesa por uma educação inclusiva, realizada pela Unesco e OEI, se materializam nos documentos muito mais como "slogans" associados à qualidade e aprendizagem, servindo para reforçar a perspectiva de avaliação externa do que realmente como preocupação com a inclusão em termos críticos e transformadores. Afirmam, ainda, que durante o governo de Mauricio Macri, esta perspectiva se acentuou com a promoção de políticas neoliberais que seguiram o mesmo rumo da agenda internacional para a educação em todo o mundo.

Continuando a reflexão sobre a educação social como concepção e a luta pela constituição de uma sociedade verdadeiramente transformada, considerando aspectos múltiplos como a garantia da educação como direito, a ampliação das reflexões considerando as políticas sociais de redistribuição da riqueza e a multiplicidade de atores que se ocupam da promoção de políticas que tenham a inclusão como discurso central, apresentamos na sequência, dois textos que se ocupam de aspectos diferenciados na perspectiva inclusiva: o primeiro defendendo a atuação de homens na educação infantil e o segundo apontando a necessidade urgente de pensar a educação para a diversidade (diríamos que também pela diversidade, considerando a importância dos sujeitos envolvidos em todo o processo).

O primeiro destes textos foi elaborado por Sílvia Adriana Rodrigues, Estefânia Manholer e Alberto Albuquerque Gomes, intitulado Em busca de identidade: educação infantil é lugar de homem? e teve o objetivo, através da narrativa de experiências de um estudante de pedagogia no estágio supervisionado, de discutir a presença masculina no trabalho docente no espaço da educação infantil. Destacando o movimento de luta das mulheres por inclusão, o magistério foi, em meados do século XX, porta de entrada para a conquista feminina de um lugar no espaço público. Os autores mostram, ainda, que este movimento de reivindicação sofre mudanças na medida em que a economia vai ganhando novos contornos e os homens vão procurar novos postos de trabalhos, mais rentáveis que o magistério. Este movimento ficou conhecido na literatura como processo de "feminização" do magistério. O texto nos ajuda a refletir sobre este importante processo, especialmente o que está implícito nele: a ideia de que a educação infantil envolve uma série de conhecimentos e características 
que não condizem com a "aspereza" e "virilidade" que seriam próprias dos homens. Os autores apresentam reflexões que demonstram a inclusão do homem no trabalho docente infantil não somente como possível - pois a naturalização destas características "próprias das mulheres" não condiz com o olhar cultural para o tema -, como necessário, uma vez que romperia com a perspectiva de que o ensino infantil seria mais condizente com uma certa "essência feminina" e que o homem não deveria, por isso, ter possibilidade de atuar neste nível de ensino. Os autores concluem que a pesquisa não pretendia defender um lugar para homens em detrimento das mulheres, senão desmistificar lugares demarcados previamente, a partir de características que supostamente seriam naturais da mulher e do homem. Os relatos do sujeito da pesquisa indicam que o trabalho em creches seria mais valorizado se o lugar fosse ocupado também por homens. Esta afirmação, como dissemos, está pautada nas percepções e experiências vividas por este sujeito no estágio supervisionado e nos fazem crer que a inclusão, desde o ponto de vista das discussões de gênero, não parte de processos naturalizados, mas aponta para necessidade de refletirmos desde o ponto de vista cultural. Ainda concluem que paira sobre o imaginário social a ideia de que para se trabalhar com crianças pequenas seria um requisito a experiência familiar com esta faixa etária o que, nesta visão, excluiria grande parte dos homens que não ocupam este lugar social em nossa sociedade.

Já o texto de Juliana S. Monteiro Vieira, Lucas de Oliveira Carvalho e Dinamara Garcia Feldens, intitulado Sintomas do Brasil contemporâneo: tensões discursivas e a educação para a diferença, debate a inclusão a partir da desconstrução de fatos históricos e contestação da ciência como elemento decisivo e principal de explicação da realidade. Tecendo críticas ao conceito de Contemporaneidade e sua relação com a educação, os autores nos ajudam a pensar a educação para a diversidade não a partir de um estatuto de cientificidade criador de narrativas fixas responsável pela criação de novas hegemonias, mas a partir de movimentos singulares que vão se constituindo em novas possibilidades de produzir-se subjetivamente e transpor representações universalizantes. A importância de pensarmos a educação para a diferença como concepção, pertencente aos princípios da educação social, portanto defensora de uma educação ao mesmo tempo inclusiva e transformadora, é parte constituinte deste dossiê e aflora com o texto de Juliana, Lucas e Dinamara, que analisam questões atuais como o discurso de intolerância que tomou o imaginário brasileiro, os pedidos de intervenção militar, dentre tantos outros despropósitos que ferem frontalmente uma sociedade fundada em respeito aos direitos e gatarias sociais, como estabelece a Constituição Federal de 1988. Por fim, os autores defendem que a educação para a diversidade fortaleça as micronarrativas da diferença e destaque o estado de crise da verdade vividos na Contemporaneidade, necessitando desconstruir os ideais 
modernos que sustentam a ideia do sujeito do conhecimento como figura primordial, possibilitando o olhar às brechas e às rachaduras e a construção de saberes mais horizontais.

O último artigo dessa seção é o estudo de Sabina Valente, intitulado Competências socioemocionais na atividade do educador social: implicações à inclusão escolar que, desde uma perspectiva da educação social como forma de auxiliar no processo de inclusão social, apresenta a importância das competências socioemocionais na formação do educador social. Por meio de uma revisão bibliográfica de produções que discorrem sobre o tema, a autora sustenta a relevância do educador social no processo de inclusão escolar, especialmente, destaca a importância de que estes profissionais tenham uma formação centrada em uma educação emocional. Apresenta, ainda, que estas aprendizagens emocionais são fundamentais para os educandos uma vez que melhoram seu desempenho geral na aprendizagem, em especial, para os alunos mais vulneráveis que, historicamente, são vítimas dos descasos da sociedade.

Este dossiê tem prosseguimento com a seção A Educação social e a reflexão sobre práticas inclusivas em diferentes contextos formativos, na qual objetivamos problematizar a educação social desde experiências que, em grande medida, são inspiradas nas concepções que temos debatido até este momento. Em outras palavras, o que queremos reforçar é que mesmo que o material esteja dividindo em duas seções, elas estão intrinsecamente relacionadas e que, portanto, pensar a educação social enquanto concepção é oferecer possibilidade de refleti-la como ação objetivada em práxis inclusivas.

Considerando sua indissociabilidade, mas destacando as práticas inclusivas, iniciamos apresentando três textos que nos levam a pensar a educação social em contextos nos quais sua existência é fruto de muita organização e luta por direitos historicamente negados. A educação quilombola e a educação do campo nos remetem a esferas de grandes conflitos, de lutas por justiça e igualdade social. Nos levam, ainda, ao lugar daqueles excluídos, desprovidos dos meios de produção, daqueles que buscam se organizar em torno de movimentos sociais para se fazer presentes, para que sejam ouvidos no contexto político e econômico. A educação, de qualidade e socialmente referenciada, é uma luta constante entre os povos do campo e quilombolas se tornando uma de suas principais bandeiras, pois passam a considerar a educação como um direito, como reconhecimento de sua existência e especificidades.

Com o desenvolvimento da alfabetização matemática desde a perspectiva de Paulo Freire e Ubiratan D’Ambrosio, Denília Andrade Teixeira dos Santos e Teodoro Adriano Costa Zanardi apresentam o texto intitulado $\mathbf{A}$ alfabetização matemática e as práticas de numeramento na comunidade quilombola de São Félix: a pedagogia crítica e o currículo 
em ação. Os autores defendem a concepção de alfabetização como processo que possibilita a organização dos saberes matemáticos que os educandos trazem consigo, de suas vidas cotidianas, incorporando-os a um novo corpo de conhecimentos, agora adquiridos pela escola, potencializando sua vida cidadã. A pesquisa realizada pelos autores indica que a escola pertencente ao Quilombo de São Félix tem enfrentado dificuldades como grande parte das escolas situadas em áreas conquistadas a partir da luta por garantia de direitos. Além dos problemas econômicos e infra estruturais, a falta de compreensão de alguns professores sobre as especificidades da educação para estas comunidades tem mostrado que nunca foi tão importante reforçar que é preciso pensar educação do campo e dos povos quilombolas, como algo construídos por e para eles. A pesquisa demonstrou que importantes conhecimentos culturais dos estudantes não ganham visibilidade na sala de aula, que a prática tradicional da matemática deixa de lado uma série de conhecimentos considerados fundamentais e que não foi possível observar qualquer relação com a realidade de luta vivida por aquelas crianças. Por outro lado, também apresentou que há importantes avanços, especialmente a partir da prática de uma das docentes participantes da pesquisa uma vez que esta demonstrou conhecer a realidade em que atua e reconhecer a importância de relacionar esta história de lutas com os conteúdos trabalhados, ainda que na maioria das vezes tenha que seguir o currículo prescrito, o considerado oficial e hegemonicamente aceito. Os autores concluem refletindo que ainda há muito o que se construir para que a educação quilombola tenha a qualidade esperada e de direito daquela população.

Os dois textos a seguir tratam do mesmo lócus de disputas e lutas: o campo. Um dos espaços que guarda, dialeticamente, os germes da transformação e o estabelecimento do latifúndio como quase intocável. O campo tem se mostrado, nas últimas décadas, o lugar que abriga os movimentos sociais de maior combatividade de nossa história, responsáveis por mudar os rumos da quase intocável dessas propriedades.

No texto de Marli Clementino Gonçalves e Neuton Alves de Araújo, intitulado Movimentos Sociais do campo, políticas educacionais e formação humana é possível observar as lutas dos movimentos sociais do campo, em especial o Movimento dos Trabalhadores Rurais Sem Terra. O texto apresenta como o MST tem se organizado, desde os anos 1990 até os dias atuais, em torno da luta pela garantia da educação escolar para seus filhos (os chamados Sem Terrinhas). Os autores apresentam diversos resultados das ações que reivindicam as práticas educacionais no contexto do campo, ainda que limitados pela investida neoliberal. Para citar algumas dessas conquistas, especialmente no campo da produção de documentos, políticas e construção de marcos legais, os autores destacam: as Diretrizes 
Operacionais para a Educação Básica nas Escolas do Campo (DOEBEC's), o Programa Nacional de Educação na Reforma Agrária (Pronera); o Decreto n. 7352/2010, que instituiu a Política Nacional de Educação do Campo e do Programa de Apoio à Formação Superior em Licenciatura em Educação do Campo (Procampo). Entretanto, fazem um importante alerta: o frágil processo de institucionalização destas ações em um estado capitalista de cariz neoliberal. Concluem os autores que o MST se constituiu, ao longo das décadas analisadas, como protagonista da reivindicação de uma educação voltada para os diferentes contextos, especialmente o campo. Também revelam que a luta pela terra serve de base material para a luta por educação e, por isso, tem sua origem na luta de classes e na necessária transformação social.

O segundo texto a tratar da educação do campo foi escrito por Maria do Socorro Pereira da Silva, e tem o título de Educação do campo e o paradigma da extensão descolonial na universidade pública. Seguindo direção semelhante ao texto anterior, a autora destaca a importância do campo e todas suas especificidades políticas, culturais, sociais e econômicas para anunciar a defesa da descolonização da extensão universitária tradicional e, em seu lugar, assumir a perspectiva da extensão popular. Para a autora, esta substituição não seria meramente a mudança de nomenclatura, mas, principalmente de concepção e, neste sentido, de compreensão do papel da universidade e sua relação com os povos do campo. A autora reivindica que esta prática de extensão popular valoriza o interconhecimento entre os saberes científicos e os saberes populares fundamentados em metodologias participativas. Em outras palavras, a formação docente universitária deveria oferecer experiências que ajudassem os acadêmicos a perceber a prática educacional como ação descolonial, contando com a participação ativa enquanto dimensão de uma pedagogia participante. Defendendo a ideia de uma Universidade Popular, a autora conclui suas reflexões defendendo a necessidade de se romper com a invisibilidade dos saberes populares, dos sujeitos e de seus contextos no sentido de articular novas lógicas de racionalidade e causalidade cientifica fundamentada nos princípios da pedagogia ação-transformação como aporte teórico-prático na construção de uma epistemologia transgressora e de uma ciência descolonial na reinvenção da universidade pública.

As práticas progressistas de educação são cada vez mais necessárias para a construção de uma educação realmente social, ou seja, voltada para a construção de possibilidades de transformação social. Portanto, a educação social, enquanto concepção, deveria estar presente em todos os campos formativos e contando com a participação importante de todos os educadores. É considerando a relevância de extrapolarmos os "muros escolares" da educação 
formal e desvelar as práticas de educação social é que apresentamos o texto elaborado por Eiza Nádila Bassoli e Vanessa Cartherina Neumann Figueiredo e o elaborado por Juliana dos Santos Rocha e Marlene Rozek.

No primeiro, intitulado Desafios do trabalho de educadoras sociais em casas de acolhimento, as autoras apresentam pesquisa realizada com nove profissionais de duas Casas de Acolhimento no Pantanal Sul-Mato-Grossense, destacando as experiências de prazer e sofrimento no trabalho de educadoras sociais. Baseando-se na teoria da Psicodinâmica do Trabalho, as autoras analisaram o sofrimento derivado do choque entre as normatizações organizacionais e as situações laborais reais experienciadas no atendimento a crianças e adolescentes. As autoras revelam que um dos problemas mais relatados entre as entrevistadas é a desvalorização de sua atividade, uma vez que poucos olham para o trabalho do educador social e nele percebem os aspectos formativos relevantes que possuem. As autoras nos oferecem explicações sobre a dificuldade de reconhecimento da relevância social do educador social destacando o distanciamento entre os pais e responsáveis, a falta de conhecimento da gestão do trabalho realizado pelos educadores sociais e a falta de regulamentação da profissão de educador social. Concluem que a falta de formação associada à sobrecarga e à natureza do trabalho, que conta com constantes conflitos, dificulta a concretização de modificações politizadas imbricadas na ressignificação do trabalho para o alcance de prazer e realização.

No segundo, intitulado A potência e a complexidade de um fazer dialógico: desafios da formação e da atuação de educadoras(es) sociais, as autoras apresentam o processo de constituição da subjetividade de educadoras(es) sociais que se posicionam dialogicamente diante de suas(seus) educandas(os). Para tanto, defendem a necessidade da instauração de um espaço que pense e discuta os processos de ensino e aprendizagem na Educação Social e, consequentemente, as possibilidades e necessidades de formação desses profissionais. Defendem, no texto, a potência e a complexidade de uma postura ética, capaz de promover a construção de um espaço dialógico na Educação Social, que reflita sobre os desafios da formação e da atuação de educadoras(es) sociais, além da promoção da participação efetiva das(os) educandas(os), respeitando sua humanidade, suas pautas e saberes, considerando-as(os) capazes de aprender e de ensinar. Concluem apontando para a necessidade de oportunizar processos formativos de qualidade, mais humanos e menos tecnicistas, que promovam uma série de conhecimentos articulados com experiências vividas no campo. Sobre estas experiências, destacam: os conhecimentos sobre aprendizagem como um processo humano; os conhecimentos históricos sobre as expressões da questão social e; os conhecimentos e experiências estéticas diversas, que confrontem as construções sociais hegemônicas. 
As práticas inclusivas que apresentamos neste dossiê convidam o leitor a refletir sobre a educação desde a perspectiva da diversidade, opondo-se à educação tradicional que objetiva homogeneizar, afastar-se do debate sobre o "eu e o outro", sobre as diferentes formas de existir no mundo. As pessoas com deficiência deveriam, nesta perspectiva, ser vistas como formas diferentes de existir no mundo e é com este prisma que apresentamos mais três textos que problematizam questões atuais como a experiência de pessoas com deficiência no contexto de pandemia de Covid-19, mas também debate aspectos históricos como as contradições entre os textos da política e as práticas de educação inclusiva realizadas.

Considerando este último aspecto, a contradição entre o texto da política e sua realização no contexto da prática, apresentamos o artigo de Hector Renan da Silveira Calixto, Amélia Escotto do Amaral Ribeiro e Tânia Suely Azevedo Brasileiro intitulado Tensões entre políticas públicas educacionais e in(ex)clusão escolar de alunos surdos: ecos de um silenciamento? Aqui os autores analisam, por meio da narrativa de professores de escolas públicas da Baixada Fluminense/RJ, tensões entre a letra do texto legislativo e as suas formas de apropriação em contextos escolares. A partir da análise dos documentos, indicam algumas características gerais: a inclusão ligada à incapacidade e às necessidades educacionais especiais; a inclusão como resposta às exclusões disciplinares; a inclusão voltada a todos os grupos vulneráveis à exclusão; a inclusão como promoção de uma escola para todos; e a inclusão como Educação para Todos. Confrontando a análise destes documentos com os discursos dos sujeitos da pesquisa, os autores concluem que, embora os textos apresentem conteúdos potencialmente relevantes para a mudança da prática, são insuficientes na medida em que não levam os professores a repensar seus posicionamentos em relação ao surdo e suas diferenças.

Já Vânia de Sousa Barbosa e Elize Keller-Franco, em texto intitulado Projeto EJA interventiva: contribuições para as práticas e políticas curriculares inclusivas argumentam que o programa denominado EJA Interventiva, desenvolvido no Distrito Federal, foi capaz de possibilitar o acesso e a permanência na educação, a continuidade da escolarização e a inserção social de estudantes com deficiência intelectual e autismo, atendendo às finalidades reparadora, equalizadora e qualificadora colocadas para a Educação de Jovens e Adultos. Interessante notarmos que os dois artigos apresentados até aqui sobre educação inclusiva de pessoas com deficiência apontam aspectos relevantes e complementares: se no primeiro indica-se que o texto da lei, quando tratado fora de um contexto, pouco contribui para a mudança das práticas formativas. Mas quando este texto se materializa em ações, como a EJA Interventiva, pode se tornar em poderosa estratégia de educação inclusiva e transformadora de hábitos. Vânia e Elize afirmam, ainda, que projetos educacionais inclusivos, articulados e desenvolvidos com a 
comunidade escolar, podem orientar atos normativos. Ou seja, defendem que o caminho reverso pode ser uma alternativa interessante: as práticas podem servir como eixos estruturantes para o desenvolvimento de políticas. Para elas, projetos educacionais inclusivos bem articulados e implementados a partir do cotidiano escolar, construídos pela escola e para a escola, podem ser bem-sucedidos e orientar políticas públicas que garantam direitos básicos para a inclusão de pessoas com deficiência.

Por fim, o texto de Vanderlei Balbino da Costa, Claudenilson Perreira Batista e Euler Rui Barbosa Tavares intitulado Narrativas de sujeitos com deficiência e isolamento social em tempos de pandemia apresenta as dificuldades que o isolamento social, decorrente da pandemia de Covid-19, tem imposto para pessoas com deficiência. Os autores iniciam o texto fazendo com que o leitor imagine como pode ser difícil o isolamento social de pessoas que, historicamente, vivem em um certo isolamento. Seria, assim, o isolamento do isolamento social. A discussão proposta no artigo ganha contornos de extrema relevância, pois dá vozes aos sujeitos com deficiência que apontam grandes dificuldades de inserção neste período de mudanças da forma de viver de todos nós. Os autores concluem - no lugar dos sujeitos que têm sofrido um processo de dupla exclusão, pois eles também possuem deficiência (visual) - que há um processo de exclusão (Re)vestido, literalmente, por duas máscaras: uma porque as pessoas com deficiência visual estão (des)providas da visão imagética dos objetos que pairam à sua frente; a outra porque as máscaras impediram de aproximar-se daqueles que amam nos diversos espaços/tempos formativos e de convivência.

Apresentando a cidade de Corumbá-MS e toda sua complexidade envolvendo as discussões sobre gênero e sexualidade, a autora Cláudia Araújo de Lima, em artigo denominado Gênero e sexualidade na Escola em tempos de globalização: Perspectivas e culturas adolescentes no Pantanal de Mato Grosso do Sul, lança luzes sobre uma experiência realizada que objetivou conhecer as representações sociais discentes da escola básica e da universidade sobre gênero e sexualidade. Através de uma disciplina ministrada na graduação em pedagogia da Universidade Federal de Mato Grosso do Sul, a autora releva a possibilidade e necessidade de articularmos os saberes produzidos na universidade e escola básica, pois, assim, será possível superar distanciamentos que ao longo da história inviabilizaram práticas inclusivas pensadas pelos e para os estudantes da educação básica e acadêmicos em processo de formação. Analisando os discursos separadamente, a autora conclui que entre os estudantes do ensino médio, foi possível perceber uma positividade quanto às questões sociais de identidade de gênero. Segundo a autora, os estudantes acreditam numa aceitação social, numa "normalidade" entre o grupo, e, apresentam um distanciamento dos espaços comunitários 
ampliados, para além da escola. Entre elas e eles a neutralidade é o comportamento mais recorrente. Não apresentaram preconceitos explícitos ou a determinação de que aquela ou aquele não faz parte do grupo. A adolescência é representada por grupos e, neste caso, as confrarias da escola não encaram a sexualidade ou o gênero como uma questão de seleção. Já entre os estudantes universitários, o contexto se apresenta de forma diferente. Muitos encaram a discussão sobre gênero e sexualidade ou diversidade como uma ação importante, outros, deixam explicito que não vão utilizar os conhecimentos apreendidos em suas atividades profissionais, seja pela condição religiosa, pela vergonha em tratar temas delicados ou o medo da reação social.

A prática da educação inclusiva também pode ser analisada desde a garantia do direito de igualdade de condições. Afastando-se do discurso hegemônico que envolve as avaliações de desempenho docente, pautados na meritocracia, o artigo de Tomás Sánchez, Luisa Carlota Santana e Martha Velasco, intitulado Avaliação como mecanismo de inclusão ou exclusão docente, analisa os discursos e as práticas avaliativas que permeiam a educação superior na Colômbia. Os autores afirmam que, ao tratarmos das políticas de avaliação docente, é preciso indagarmos sobre as condições que os profissionais da educação possuem para serem avaliados em condições de igualdade de oportunidades, resultando em um processo contínuo de desenvolvimento na carreira. Analisando as condições como se desenvolvem as políticas colombianas para o ensino superior, os autores alertam que tem ocorrido ações com discursos inclusivos e práticas excludentes. Esta dicotomia ocorreria em virtude das práticas avaliativas atualmente desenvolvidas na Colômbia que passam a reconhecer a qualidade da docência e seus saberes somente a partir destas avaliações de desempenho completamente desiguais e excludentes. Concluem que os discursos sobre avaliação docente se distanciam da realidade vivida pelos sujeitos, uma vez que a instituição pesquisada insere uma cultura avaliativa desde o ingresso do docente que resulta na adaptação a uma série de exigências institucionais e requisitos que são excludentes porque obrigam sua adoção em virtude de questões contratuais, estabilidade na instituição e condições de trabalho. Finalmente, indicam que a inclusão educativa se constitui numa política de formação docente para a diversidade e, consequentemente, uma avaliação docente que considere toda a diversidade e suas condições socioculturais particulares.

O texto que encerra este dossiê amplia, ainda mais, o escopo de atuação da educação social e chega às margens da "brincança" termo que, de acordo com as autoras, pode ser atribuído a uma manifestação artístico-cultural fundada na Tradição Oral, que mistura religiosidade popular e o que é tido para o catolicismo como "profanidade". Através do artigo 
intitulado A brincança dos Embelêcos: vozes políticas e epistemológicas dos subalternos, é apresentada a brincança dos Embelêcos de Moita Bonita-SE como uma prática cultural que, na perspectiva dos brincantes, é subversiva e revolucionária. As autoras constroem seu texto a partir de uma perspectiva pós-colonial, oferecendo a seus leitores a possibilidade de compreender que os subalternos só poderão falar, quando falarem em sua própria língua, com seus sistemas explicativos, em sua própria cultura. Também convidam para reflexões sobre o impacto da invisibilidade sistemática, naturalizada pelo colonialismo acadêmico em relação aos saberes de Tradição Oral. Ouvindo as narrativas dos mestres Griôs ${ }^{5}$, as autoras concluem que as manifestações culturais de Tradição Oral podem ser um dos espaços para expressar a voz "não-dita". Voz que fala através de saberes corporais, que cantam, que dançam e expressam seu cotidiano, suas memórias, seus mitos, seus gestos e sua ancestralidade.

Por fim, cabe-nos convidar o leitor para uma ótima viagem através das temáticas aqui presentes!

\section{REFERÊNCIAS}

DALE, R. Globalização e educação: demonstrando a existência de uma "cultura educacional mundial comum" ou localizando uma "agenda globalmente estruturada para a educação"? Educação \& Sociedade, Campinas, v. 25, n. 87, p. 423-460, maio/ago. 2004.

DÍAZ, A. S. Uma aproximação à Pedagogia- Educação Social. Revista Lusófona de Educação, Lisboa (Portugal), v. 7 n. 7, 2006. Disponível em: https://revistas.ulusofona.pt/index.php/rleducacao/issue/view/64. Acesso em: set out. 2020.

FRIGOTTO, G. Educação e a crise do capitalismo real. São. Paulo: Ed. Cortez, 1995.

GRAMSCI, A. Cadernos do cárcere. Maquiavel: notas sobre o estado e a política. Rio de Janeiro: Civilização Brasileira, 2011. v. 3.

KOERNER, A. Ordem política e sujeito de Direito no debate sobre direitos humanos. Lua Nova, n. 57, 2002.

KUENZER, Acacia Zeneida. Exclusão includente e inclusão excludente: a nova forma de dualidade estrutural que objetiva as novas relações entre educação e trabalho. In Saviani, Dermeval; Sanfelice, José Luiz; Lombardi, José Claudinei. (Org.). Capitalismo, trabalho e educação. 2ed. Campinas: Autores Associados, 2006. P. 77-96.

MARTINS, J. S. Exclusão social e a nova desigualdade social. São Paulo: Paulus, 1997.

${ }^{5}$ Segundo as autoras, Griô ou Mestre(a) é todo(a) cidadão(ã) que se reconheça e seja reconhecido(a) pela sua própria comunidade como herdeiro(a) dos saberes e fazeres da tradição oral e que, através do poder da palavra, da oralidade, da corporeidade e da vivência, dialoga, aprende, ensina e torna-se a memória viva e afetiva da tradição oral, transmitindo saberes e fazeres de geração em geração, garantindo a ancestralidade e identidade do seu povo

RIAEE - Revista Ibero-Americana de Estudos em Educação, Araraquara, v. 15, n. esp. 3, p. 2146-2166, nov., 2020. E-ISSN: $1982-5587$. 
MÉSZÁROS, I. A educação para além do capital. Trad Isa Tavares. São Paulo: Boitempo, 2005.

RAMOS, M. N. A pedagogia das competências: autonomia ou adaptação? São Paulo:

Cortez, 2001.

RIBEIRO, M. Exclusão e educação social: conceitos em superfície e fundo. Educação \& Sociedade, Campinas, v. 27, n. 94, p. 155-178, abr. 2006. DOI:

http://dx.doi.org/10.1590/S0101-73302006000100008

RIBEIRO, M. O caráter pedagógico dos movimentos sociais. Serviço Social e Sociedade, São Paulo, n. 58, p. 41-71, 1998.

SAVIANI, D. Escola e democracia. São Paulo; Campinas: Cortez: Autores Associados, 1988.

UN. Universal Declaration of Human Rights (UDHR). UN General Assembly. Paris, 1948. Disponível em: http://undocs.org/en/A/RES/217(III). Acesso em: 10 set. 2020.

\section{Como referenciar este artigo}

SANTOS, F. A. S.; MARTINS, B. A.; KASSAR, M. C. M. Olhares para a diversidade, inclusão escolar e exclusão social: contribuições da educação social. Revista Ibero-Americana de Estudos em Educação, Araraquara, v. 15, n. esp. 3, p. 2146-2166, nov., 2020. E-ISSN: 19825587. DOI: https://doi.org/10.21723/riaee.v15iesp3.14418

Submetido em: 20/07/2020

Revisões requeridas em: 30/08/2020

Aprovado em: 29/09/2020

Publicado em: 30/10/2020 